\title{
A word to the wise
}

Philip T. Smith

Knowledge of Language: Its Nature, Origin, and Use. By Noam Chomsky.

Praeger: 1986. Pp.307. Hbk \$29.95, £27.50; pbk \$9.95, £9.95.

ArE languages real? This may seem an unnecessary question to the owner of the Oxford English Dictionary, to the librarian, to the court reporter or to the man who has imprudently ignored a sign reading "Beware of the Dog". But there are unresolved issues about the status of a language that are remarkably difficult to deal with. The linguist Martin Joos put the matter well when he distinguished "hocus pocus" and "God's truth" approaches to language: hocus pocus linguists are looking for patterns in a language, but these patterns have no privileged philosophical or psychological status and any other set of patterns that fits the data is equally valid; God's truth linguists believe that there is a unique structure waiting to be discovered.

Up to a point these are problems common to all scientific endeavours: a physicist may worry about the extent to which atoms are "really" like billiard balls, or a chemist about the status of a concept such as valency. For the physicist or the chemist, however, direct observations of the world around them constrain their theorizing: the concepts of the billiard ball atom or of valency will be accepted, modified or discarded according to how well they contribute to successful theories of physical phenomena. With language things are more complicated because there is no general agreement as to what observations are relevant to our theorizing. Is it the external manifestations of a language, the totality of utterances of a particular speech community, that should form the basis of our testing of linguistic theories? Or is it the lesstangible internal knowledge of a language possessed by an individual that should be the starting point? Tradition, convenience and common sense say we should be concerned with the external manifestations of language: it is Noam Chomsky's most important contribution to linguistics that he equates the goals of linguistics with the study of internal knowledge.

Chomsky has always thrived on controversy. His contempt for behaviourism, reflected in his 1959 review of B.F. Skinner's book Verbal Behavior, has been extended to most of experimental psychology, which he believes to be merely the pointless gathering of data. He thrives, too, on the paradoxical statement (for example his claim that English orthography is "near optimal" would amaze the millions of people who have had trouble learning to read English and to spell it correctly). But perhaps the greatest paradox of Chomsky's work is that his theory of language is based on the need to explain how almost any child can learn its mother tongue with relative ease, at the same time using as data for his theory only the intuitions of a small number of highly educated adults like himself.

Chomsky's central argument runs as follows. We need to move away from the conception of language as an external object (an "E-language") because studying such a language is merely an exercise in discovering patterns in the data, without being able to explain why such patterns are there and without being able to choose between alternative competing descriptions of the data. Instead, argues Chomsky, we must conceive of language as an internal state of an individual's knowledge (an "I-language"). The goal of linguistic theory is to describe this knowledge in terms of a universal grammar (UG) which is common to all human languages and to all human beings. Universal grammar is not totally inflexible, otherwise we would all speak the same language; rather, $U G$ contains certain parameters that differ between languages. The child's goal is to discover what values these parameters take for the language being presented to him; the linguist's goal is to discover the form of $\mathrm{UG}$ and to write grammars for particular languages which incorporate the principles laid down in UG. Simultaneously, this argument sketches the solution to two very difficult problems. First, how can a child learn a language so quickly on so little evidence? (answer: the number of possible grammars the child has to consider is radically reduced by UG, and UG is part of the child's innate endowment). Second, how can a linguist choose between competing descriptively adequate grammars for a single language? (answer: choose the grammar that is most in harmony with the principles of UG). Thus when linguists sit in their offices in MIT arguing about the appropriate analysis of an English sentence such as "John is too stubborn to expect anyone to talk to", their concerns are similar to those of a naked child living in a community whose language is spoken by a few hundred people in the depths of Papua New Guinea. Both need access to UG to succeed.

In this, his latest book, Chomsky has restated his views on the nature of language, and linguists who have kept in touch with his work in recent years will find little that is new to them. Rather, the main achievement of the book is the long central chapter which sets out with great lucidity the development of ideas about the nature of language ("generative grammar") over the past 30 years. Particularly noticeable is the shift from using many specialist rules to account for facts about English to an emphasis on general principles that are incorporated in UG. In a later chapter Chomsky deals at length with the notion of what it means to obey a rule, and counters objections from philosophers, principally Wittgenstein, Searle and Dummett.

Linguists and psychologists ignore Chomsky's work only at their peril, but I have one substantial reservation about his current theoretical position. This is the reliance on the notion of a "best" grammar: the child or the linguist is supposed to select the best among possibly several competing grammars, the criteria for "best" being incorporated in the theory of UG. Chomsky cannot yet spell out what

\section{IMAGE UNAVAILABLE FOR COPYRIGHT REASONS}

"Blocks world": a highly simplified domain which is used by workers in artificial intelligence to explore the ways that perception, thought and actions (for example in stacking the shapes) can be modelled and linked by the computer. The illustration is taken from Language. Writing, and the Computer: Readings from Scientific American published by W.H. Freeman. Price is hbk $\$ 20.95, £ 20.95 ; p b k \$ 12.95, £ 12.95$. 